Special Issue of the 6th International Congress \& Exhibition (APMAS2016), Maslak, Istanbul, Turkey, June 1-3, 2016

\title{
The Kinetics of Spinel Formation of Algerian Halloysite by Differential Thermal Analysis
}

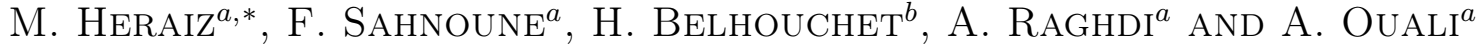 \\ ${ }^{a}$ Physics and Chemistry of Materials Lab, Department of Physics, University Mohamed Boudiaf of M'sila, \\ 28000, M'sila, Algeria \\ ${ }^{b}$ Laboratoire des Matériaux non Métalliques, I. O. M. P, Université Ferhat Abbas Sétif 1, 19000, Sétif, Algeria \\ The kinetics of spinel (Al-Si) crystallization from Algerian halloysite (DD1) was investigated using differential \\ thermal analysis. Experiments were carried out on samples between room temperature and $1400^{\circ} \mathrm{C}$ with constant \\ heating rate from 2 to $20^{\circ} \mathrm{C} \mathrm{min}{ }^{-1}$. The activation energies measured from isothermal and non-isothermal tre- \\ atments were 1054.85 and $1140 \mathrm{~kJ} \mathrm{~mol}^{-1}$, respectively, for the spinel (Al-Si) formation. The Avrami constant $n$ \\ obtained by the Ligero method and the $m$ parameter obtained by the Matusita method were about 2 for spinel \\ crystallization. This value indicates that the crystallization mechanism of $\mathrm{Al}-\mathrm{Si}$ spinel phase proceeds by bulk \\ nucleation of the phase formation with a constant number of nuclei and that the three-dimensional growth of \\ crystals is controlled by diffusion.
}

DOI: 10.12693/APhysPolA.131.139

PACS/topics: 81.70.Pg, 81.20.Ev, 82.20.-w

\section{Introduction}

Halloysite has the same theoretical chemical composition as kaolinite except for its higher water content. The unit formula for halloysite can be expressed as $\mathrm{Al}_{2} \mathrm{Si}_{2} \mathrm{O}_{5}(\mathrm{OH})_{4}-n \mathrm{H}_{2} \mathrm{O}$, where $n=2$ for halloysite $(10 \AA)$ and $n=0$ for halloysite $(7 \AA)[1]$. Halloysite typically formed by the hydrothermal change of alumino-silicate minerals [2]. It can occur intermixed with dickite, kaolinite, montmorillonite and other clay minerals. The halloysite is an important raw material for the production of ceramics, refractories and many products in different fields of industry. Utilization of calcined clays as pozzolanic admixtures for cement has been known since the Roman era [3]. Furthermore, halloysite can be utilized for trash management [4], geopolymers preparation, and geopolymer based composites [5]. The objective of the present work is to investigate the kinetics of spinel formation from the Algerian halloysite through isothermal treatments using differential thermal analysis (DTA) and calculate the activation energy and the Avrami parameters for the different transformations.

\section{Materials and experimental procedures}

Algerian raw halloysite (DD1, from Djabal Debagh) was used in this investigation. The ball milling technique was used to prepare a homogeneous powder of halloysite. The raw powder was charged into zirconia vials together with 15 zirconia balls. The ball-to-powder weight ratio was maintained as 10:1 and ethanol were added at a ratio of 2:1. The ball-milling experiments were performed in

\footnotetext{
*corresponding author; e-mail: heraizme@yahoo.fr
}

a high-energy planetary ball mill (Fritsch P6) and were carried out at room temperature. The milled powder was dried at $150^{\circ} \mathrm{C}$ for $24 \mathrm{~h}$. DTA was performed on the samples using a SETARAM Labsys thermal analyser. The samples were heated from room temperature up to $1400^{\circ} \mathrm{C}$, at heating rates of $2,5,10,15$, and $20^{\circ} \mathrm{C} / \mathrm{min}$.

\section{Kinetic methods}

The study of the kinetics of crystallization is provided by the Johnson-Mehl-Avrami (JMA) model, in amorphous materials by differential scanning calorimetry (DSC) and differential thermal analysis, and has been vastly discussed in the literature [6-9]. Various models have been proposed to determine kinetic parameters for non-isothermal conditions. These include the Kissinger, Ligero, and Matusita methods [7-9]. Aforementioned models have been used previously in studies of the kinetics of glass crystallization for various glass-ceramic systems [10], in the development of glass-ceramics from wastes [11], and among others, in studying the crystallization of mullite from different materials [12]. For many transformations in the solid state, dependence of crystallization in relation to time has been the same. That is a sigmoidal curve result when the crystallized fraction is plotted as a function of time. Mathematically speaking, the crystallized fraction at time $t$, with the velocity of crystallization constant, is expressed by the JMA equation as follows [13]:

$$
x(t)=1-\exp \left(-(k t)^{n}\right),
$$

where $n$ is the Avrami exponent, which describes the mechanism of crystallization and provides qualitative information on the nature of the processes of nucleation and growth of the crystals, whereby this parameter varies between 0.5 and 4 . Consequently by following the methodology of Ligero et al. and Kissinger et al. $[7,8]$ as well as 
the modified form of Matusita [9] as shown in Romero et al. [13], it has been possible to determine the activation energies and the kinetic parameters.

\section{Results and discussion}

Figure 1 shows the typical DTA curves of halloysite powder during heating from room temperature to $1400^{\circ} \mathrm{C}$ at a heating rate of $15^{\circ} \mathrm{C} / \mathrm{min}$. These experiments show that the decomposition process of the halloysite takes place in four main steps. First endothermic peak, in the range $323-420 \mathrm{~K}$, corresponds to the release of water adsorbed on the surface of the particles (dehydration) [14]. Structural decomposition of halloysite occurs in the second endothermic peak between 705 and $880 \mathrm{~K}$. The peak centered at about $824.5 \mathrm{~K}$ is assigned to the dehydroxylation of halloysite and the formation of metahalloysite. An exothermic peak, between 1231 and $1308 \mathrm{~K}$, centered at about $1264.7 \mathrm{~K}$ could be explained by the formation of amorphous $\mathrm{SiO}_{2}$ and $\mathrm{Si}-\mathrm{Al}$ spinel with mullitelike composition [14]. An exothermic peak, between 1514 and $1614 \mathrm{~K}$, centered at about $1454.5 \mathrm{~K}$ is assigned to the transformation from amorphous silica to crystalline phase called cristobalite.

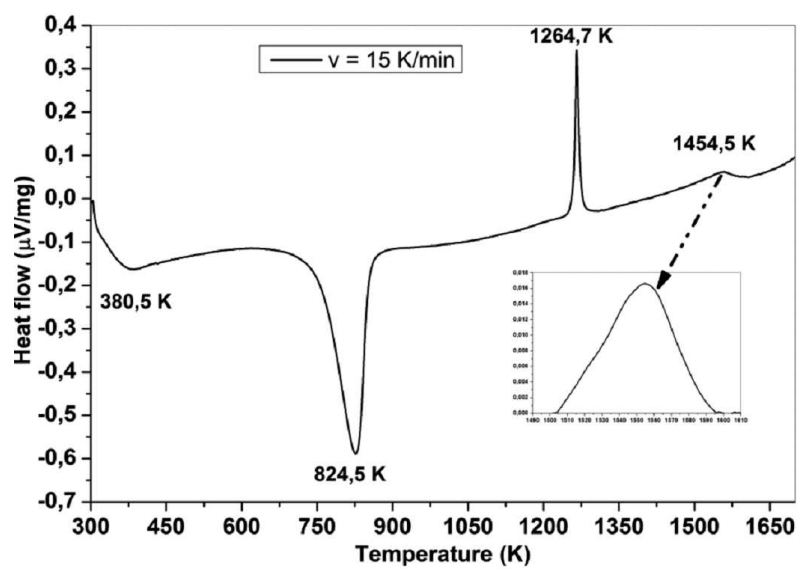

Fig. 1. DTA curve for halloysite.

\subsection{Isothermal kinetics}

The DTA curves, as a function of temperature at heating rates of $2,5,10,15$, and $20^{\circ} \mathrm{C} / \mathrm{min}$, were used to calculate the activation energy for the formation of spinel phase. The maximum temperature $\left(T_{m}\right)$, at different heating rates, for the transformation of metahalloysite to spinel, shown in Fig. 2 was obtained from the DTA curves..

The variation of crystallised fraction of spinel formation with temperature under different heating rates is presented in Fig. 3. The crystallised fraction, $x$, was determined from DTA results as

$$
x=S_{T} / S_{0},
$$

where $S_{T}$ symbolizes the area of the peak in the DTA curve at temperature $T$, and $S_{0}$ is the total area under

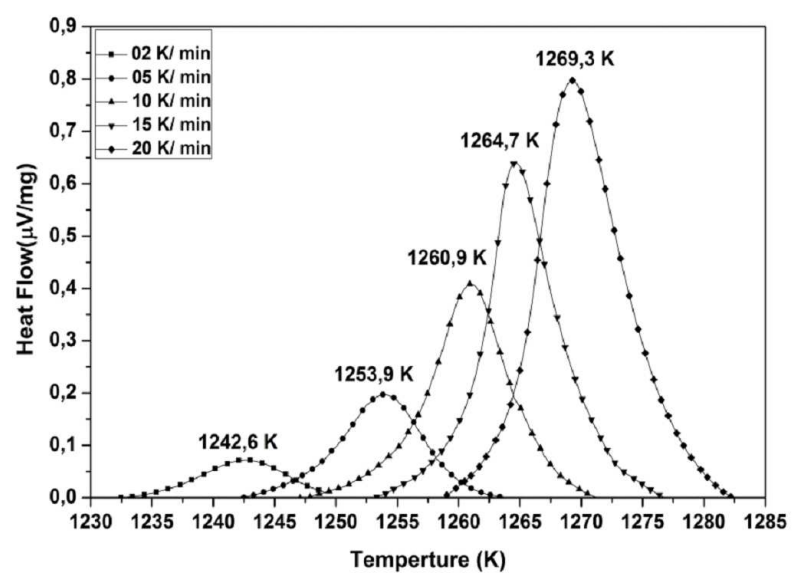

Fig. 2. DTA curves for the transformation of metahlloysite to spinel at different heating rates.

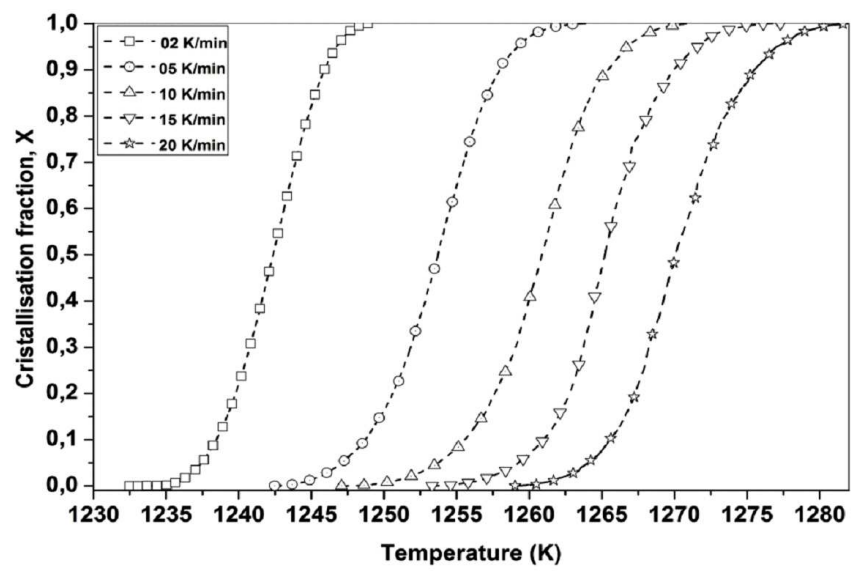

Fig. 3. Variation of crystallised fraction of spinel, with temperature for halloysite powder under different heating rates.

the peak. The crystallised fraction, $x$, at a temperature $T$ differs at different heating rates and hence the curves of $\mathrm{d} x / \mathrm{d} t$ versus time are also different as shown in Fig. 4, which depicts the growth rate of spinel with time at different heating rates. The crystallization rate increases with the heating rate increase

Figure 5 shows the plot of $\ln (\mathrm{d} x / \mathrm{d} t)$ versus $1 / T$ at the same value of crystallised fraction, $x$, from the experiments at different heating rates as proposed by Ligero et al. [7]. The values of the activation energy, $E_{A}$, for different crystallised fraction, were calculated by the average

\section{TABLE I}

Values of activation energy $E_{A}[\mathrm{~kJ} / \mathrm{mol}]$ and correlation coefficient $R^{2}$ for different crystallized fractions.

\begin{tabular}{c|c|c|c|c|c|c}
\hline \hline$x$ & 0.4 & 0.5 & 0.6 & 0.7 & 0.8 & 0.9 \\
\hline$R^{2}$ & 0.998 & 0.998 & 0.998 & 0.998 & 0.997 & 0.997 \\
$E_{A}$ & 1160.25 & 1146.87 & 1087.93 & 1054.52 & 985.92 & 893.64
\end{tabular}




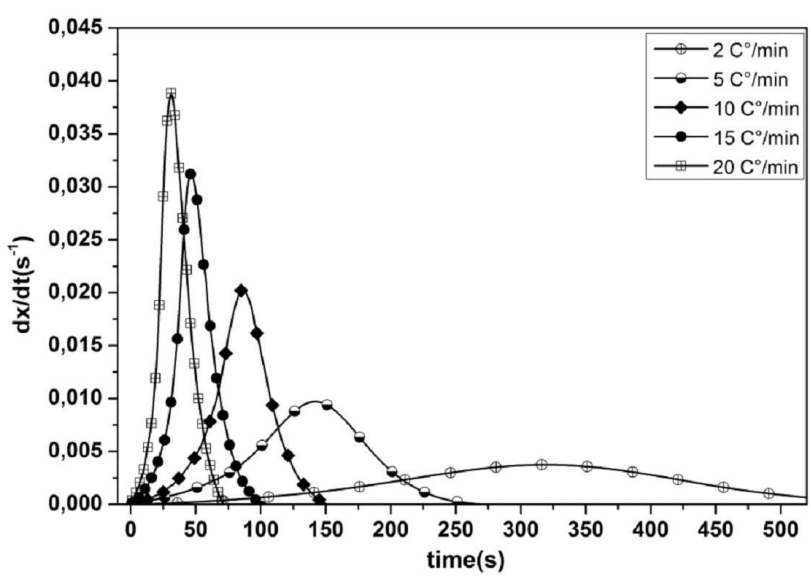

Fig. 4. Growth rate of spinel, with time for halloysite (DD1) powder at different heating rates.

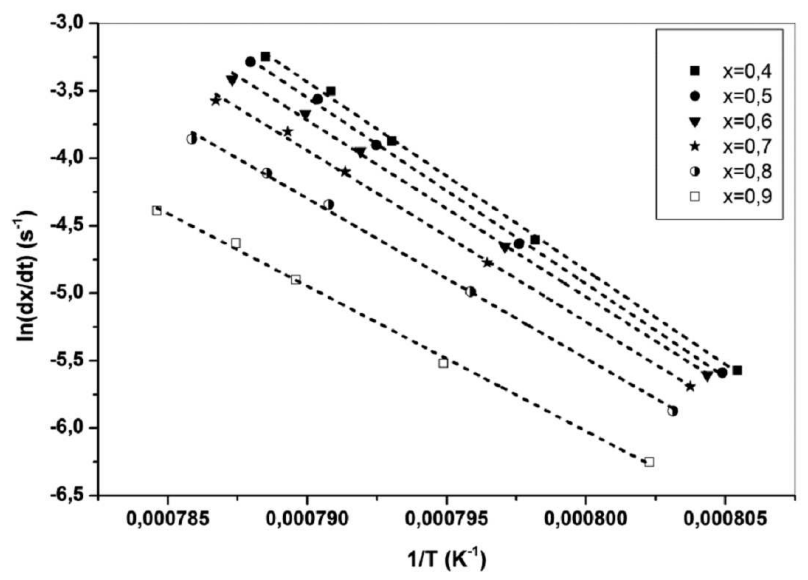

Fig. 5. Plot of $\ln (\mathrm{d} x / \mathrm{d} t)$ versus $1 / T$ at the same value of crystallised fraction, $x$, from the experiments at different heating rates for spinel.

of the slopes of the lines and are presented in Table I. The value of the activation energy is $1054.86 \mathrm{~kJ} / \mathrm{mol}$ for the formation of spinel.

The Avrami parameter, $n$, was determined by the selection of many pairs of $x_{1}$, and $x_{2}$ that satisfied the condition $\ln \left(k_{0} f\left(x_{1}\right)\right)=\ln \left(k_{0} f\left(x_{2}\right)\right)$. The average values of $n$ for each heating rate are presented in Table II. The average Avrami parameter is 2.18 for spinel formation, which suggests that the crystallization process, in halloysite powder, is controlled by diffusion growth.

Figure 6 shows the plots of $\ln \left(\phi / T_{m}^{2}\right)$ and $\ln \left(\phi^{n} / T_{m}^{2}\right)$ versus $1 / T_{m}$ according to the Kissinger, and Matusita and Sakka equations [8,9], respectively. The activation

TABLE II

Values of the Avrami parameter $n$ for different heating rate $\phi\left[{ }^{\circ} \mathrm{C} \min ^{-1}\right]$.

\begin{tabular}{c|c|c|c|c|c}
\hline \hline$\phi$ & 2 & 5 & 10 & 15 & 20 \\
\hline$n$ & 2.23 & 2.31 & 2.38 & 2.12 & 1.87
\end{tabular}

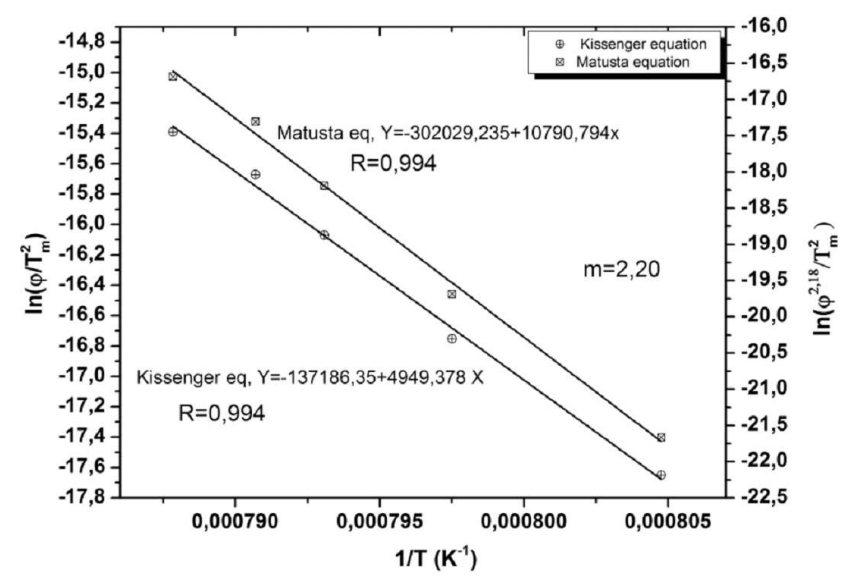

Fig. 6. Plots of $\ln \left(\phi / T_{m}^{2}\right)$ and $\ln \left(\phi^{n} / T_{m}^{2}\right)$ versus $1 / T_{m}$, according to Kissinger and Matusita equations, respectively, for spinel.

energy calculated from the slope of the Kissinger plot is $1140 \mathrm{~kJ} / \mathrm{mol}$ for spinel formation, which is a good conformity with this value $1054.85 \mathrm{~kJ} / \mathrm{mol}$, for spinel formation, estimated by the Ligero method. According to the Matusita equation, the activation energy for spinel ( $\mathrm{Al}-\mathrm{Si}$ ) formation was reported in the literature [15]. Ptáček et al. [16] reported activation energy of $856 \mathrm{~kJ} / \mathrm{mol}$ for spinel (Al-Si) formation from metakaolinite. The parameter $m$ was found to be 2.20 for spinel formation in halloysite powder. The growth morphology parameters, $n$ and $m$, were both about 2.0, indicating that the bulk nucleation was dominant in spinel formation, and the crystal growth was controlled by diffusion.

\section{Conclusion}

DTA was used to investigate the thermal decomposition of halloysite at different heating rates under an argon atmosphere. Halloysite was transformed to metahalloysite on heating to $873 \mathrm{~K}$ and the peak temperature of the dehydroxylation was at $799 \mathrm{~K}$. The metahalloysite transformed into aluminium-silicon spinel and amorphous silica after the decomposition at $1264 \mathrm{~K}$. The crystallization kinetics and growth mechanism of spinel formation in halloysite was investigated based on isothermal method. The activation energies of spinel formation in halloysite calculated using isothermal and non-isothermal treatments were 1054.85 and $1140 \mathrm{~kJ} \mathrm{~mol}^{-1}$, respectively. The average value of the growth morphology parameters $n$ and $m$ were both about 2.0, indicating that the bulk nucleation was dominant in spinel formation, and the crystal growth was controlled by diffusion.

\section{References}

[1] A.F. Peixoto, A.C. Fernandes, C. Pereira, J. Pires, C. Freire, Micropor. Mesopor. Mater. 219, 145 (2016).

[2] F.P. Kerr, Clays Clay Miner. 1, 19 (1952).

[3] A. Shvarzman, K. Kovler, G.S. Grader, G.E. Shter, Cement Concr. Res. 33, 405 (2003). 
[4] A.E. Osmanlioglu, Waste Manage. 22, 481 (2002).

[5] Z. Zuhua, Y. Xiao, Z. Huajun, C. Yue, Appl. Clay Sci. 43, 218 (2009).

[6] R.A. Silva, S.R. Teixeira, A.E. Souza, D.I. Santos, M. Romero, J.Ma. Rincón, Appl. Clay Sci. 52, 165 (2011).

[7] R.A. Ligero, J. Vazques, M. Casas-Ruiz, R. JimenezGaray, J. Mater. Sci. 26, 211 (1991).

[8] H.E. Kissinger, J. Res. Natl. Bur. Stand. 57, 217 (1956).

[9] K. Matusita, S. Sakka, J. Non-Cryst. Solids 38-39, 741 (1980).

[10] A. Goel, E.R. Shaaban, F.C.L. Melo, M.J. Ribeiro, J.M.F. Ferreira, J. Non-Cryst. Solids 353, 2383 (2007).
[11] M. Romero, J. Kovacova, J.Ma. Rincón, J. Mater. Sci. 43, 4135 (2008).

[12] A.L. Campos, N.T. Silva, F.C.L. Melo, M.A.S. Oliveira, G.P. Thim, J. Non-Cryst. Solids 304, 19 (2002).

[13] M. Romero, J. Martin-Marquez, J.Ma. Rincon, J. Europ. Ceram. Soc. 26, 1647 (2006).

[14] K. Samir, L. Salima, M.K. Kheira, S. Jacques, G.B. Isabelle, K. Amine, Micropor. Mesopor. Mater. 158, 47 (2012).

[15] P. Ptáček, F. Šoukal, T. Opravil, J. Havlica, J. Brandštetr, Powder Technol. 243, 40 (2013).

[16] P. Ptáček, F. Šoukal, T. Opravil, M. Noskova, J. Havlica, J. Brandštetr, J. Solid State Chem. 183, 2565 (2010). 